\title{
Diagnostic dilemmas in helminthology: what tools to use and when?
}

Bergquist, Robert; Johansen, Maria Vang; Utzinger, Jürg

Published in:

Trends in Parasitology

DOI:

10.1016/j.pt.2009.01.004

Publication date:

2009

Document version

Early version, also known as pre-print

Citation for published version (APA):

Bergquist, R., Johansen, M. V., \& Utzinger, J. (2009). Diagnostic dilemmas in helminthology: what tools to use and when? Trends in Parasitology, 25(4), 151-156. https://doi.org/10.1016/j.pt.2009.01.004 
TREPAR-D-00222: 5/12/2008 (Revised and resubmitted to Trends in Parasitology - Opinion)

DOI: 10.1016/j.pt.2009.01.004

\title{
Diagnostic dilemmas in helminthology: what tools to use and when?
}

\section{Robert Bergquist $^{1}$, Maria Vang Johansen ${ }^{2}$ and Jürg Utzinger ${ }^{3}$}

\author{
${ }^{1}$ Ingerod, Brastad, Sweden
}

${ }^{2}$ DBL-Centre for Health Research and Development, Faculty of Life Sciences, University of Copenhagen, Copenhagen, Denmark

${ }^{3}$ Department of Public Health and Epidemiology, Swiss Tropical Institute, Basel, Switzerland

\section{Corresponding author: Bergquist, R. (robert.bergquist@yahoo.se)}

\section{Abstract}

Available data regarding the distribution, prevalence and severity of various diseases are based on the performance and operational characteristics of the diagnostic techniques applied; a fact particularly apparent in the study of helminth infections. An important lesson learnt from the efforts to rein in dracunculiasis, lymphatic filariasis and schistosomiasis is that the diagnostic approach changes as further progress is made towards control and ultimate elimination of the disease. This insight prompted the opinion presented here, which highlights diagnostic dilemmas in helminthology related to the stage of control achieved, and sets out some research needs.

Key words: helminth infections, diagnosis, control, elimination, microscopy, serology, specificity, sensitivity, prevalence 
Choice of diagnostic assays

New and ambitious goals have been set for the control of infectious diseases in the developing world by governments and international donor agencies in collaboration with the World Health Organization (WHO). Significant progress has been made but there is a tendency to emphasize mainly drug treatment, and also vaccines, while the importance of quality-assured diagnostic tests is often neglected [1]. Yet, the more successful a control programme becomes, the more critical is the need for an accurate assessment of the epidemiological situation.

The helminthic diseases require diverse diagnostic approaches. For example, while serology constitute a valuable adjunct to the clinical diagnosis of echinococcosis, trichinellosis and toxocariasis [2], the local elimination of various helminth infections such as dracunculiasis [3], lymphatic filariasis [4,5] and schistosomiasis $[4,6,7]$ highlights the need for adjusting the diagnostic capability to the different stages of active control.

The focus of this opinion article is on schistosomiasis and the main soil-transmitted helminthiases (ascariasis, hookworm disease and trichuriasis) because these diseases are still widespread [8-10], while activities to control them have gained momentum due to the World Health Assembly resolution WHA54.19 of May 2001, which urges member states to regularly treat at least $75 \%$ of school-aged children and other high-risk groups with praziquantel against schistosomiasis and albendazole/mebendazole against soil-transmitted helminthiases [11]. The food-borne trematodiases (e.g. clonorchiasis, fascioliasis, opisthorchiasis and paragonimiasis) are also discussed as this group comprises serious, yet truly neglected tropical diseases which, in addition to their veterinary significance, constitute an emerging public health threat in many parts of the world [12-16]. 
The choice of a diagnostic assay should be governed by the objective of the activity. Indeed, the proper diagnosis of an infection is paramount for all aspects of its prevention and control. Moreover, the evaluation of efficacy and community-effectiveness of interventions, verification of local disease elimination and early detection of resurgence strongly depends on reliable diagnostic tools $[17,18]$. However, while the implementation of a complex diagnostic approach based on the highest possible combination of sensitivity and specificity can be defended from a research point of view, even when time-consuming and expensive, an approach useful in practise is almost always a compromise between quality and quantity as the techniques needed for large-scale application must be based on cost-effectiveness, i.e. time and resources required per test, simplicity and robustness. The dilemma represented by this need for compromise is related to the nature of the infection and the stage of control achieved.

The heart of the matter is the required, continuous adaption of the diagnostic focus to the state of control, taking into account the prevailing constraints in terms of available resources. Fig. 1 highlights this by showing the various stages of a hypothetical helminth control programme juxtaposed with the type of diagnostic tools that must be employed to reach the set goals.

\section{From morbidity to post-transmission}

In 2002, Engels and colleagues [19] outlined the control of schistosomiasis as a series of consecutive steps moving from morbidity control to elimination of infection as a public health threat. This framework has here been expanded to include also the soil-transmitted helminthiases and the food-borne trematodiases. Underlying reasons are the considerable geographical overlap of these infections, the similar tools for diagnosis used at the onset of control activities (e.g. microscopy of stool samples) and the similar public health measures 
applied (e.g. large-scale administration of anthelminthic drugs when morbidity reduction is the prime objective) [20,21]. Post-transmission control is not depicted in the figure as this stage is limited to a relatively small number of patients but it should be realized that it will require interventions for a prolonged period of time, particularly in the case of schistosomiasis and the food-borne trematodiases [22]. The idea to collate this information (Fig. 2) is in line with the growing emphasis on integrating the control of the so-called neglected tropical diseases $[4,10,23-25]$. Currently used techniques are depicted in the boxes to the right in the figure, while the entries to the left are still tentative.

\section{Diagnostic dilemmas}

\section{Morbidity control - questionnaires and standard diagnostic tests}

When control of schistosomiasis was first attempted, eradication was the pronounced goal, at least by some eminent scientists at the time [26]. However, the failure of this approach was not due to a diagnostic dilemma but depended on the incongruence between objective and tools. The problem was circumvented by the advent of praziquantel which permitted a change of tactics, i.e. substituting morbidity for transmission as the focus of control in highly endemic areas [27]. This strategy, relying on mass administration of safe and efficacious drugs donated or provided at very low cost $[4,7,10]$, is still recommended in settings where the proportion of those infected surpasses a given threshold (e.g. $>50 \%$ of school-aged children infected) [11]. With this diagnostic scenario, cost and simplicity are more important than sensitivity leading to the utilization of community-based questionnaires with the results followed-up by standard parasitological examinations of excreta (e.g. stool, urine and sputum). That these results are not fully reliable with respect to prevalence and give even less information on the level of transmission must be weighed against the importance of rapidly identifying those in most need of treatment. 
Interviewing schoolchildren about blood in the urine has proved generally accurate and cost-effective for the rapid identification of high-risk communities of urinary schistosomiasis [28]. While a similar approach, focused on dietary habits (e.g. consumption of raw or undercooked fish), could be a quick way to identify populations at risk of clonorchiasis [29], geographical and ethnographical differences present an unforeseen dilemma. For example, whereas communities suffering from opisthorchiasis in Thailand were able to perform selfdiagnosis leading to treatment-seeking practices, this was not the case in Laos where opisthorchiasis-specific symptoms were vague [30] leading to the conclusion that the questionnaire approach must be locally assessed before large-scale implementation. Thus, parasitological diagnostic tools are still needed for assessing cure after treatment and, in the longer perspective, dependable disease surveillance.

Faecal smears and Kato-Katz thick smears are widely used direct methods for diagnosing intestinal schistosomiasis, the common soil-transmitted helminthiases and most food-borne trematode infections [31,32]. While a strong bias towards false negatives would falsify the outcome, even a considerable proportion of false positives would not compromise the costeffectiveness of this approach since the extra drug expense is marginal in today's prices (e.g. US\$ $0.10-0.20$ for treating a school-aged child with praziquantel) $[33,34]$. The danger of a misinterpretation of the epidemiological situation, however, is clearly present and this risk increases as the numbers and infection intensities are brought down.

Some further diagnostic dilemmas with reference to stool examinations at the stage of morbidity control are worth mentioning. First, because infections with multiple species are the norm rather than the exception, there is a need for well-trained laboratory technicians and quality control measures to ascertain accurate, species-specific helminth diagnosis. This issue is particularly relevant in settings characterized by a high diversity of food-borne trematodes [35]. Second, while Kato-Katz thick smears should be read shortly after slide preparation 
(preferably within $30 \mathrm{~min}$ ) for hookworm eggs which would otherwise have disintegrated, longer clearing times (sometimes several hours) are warranted for the diagnosis of Schistosoma mansoni, as well as Ascaris lumbricoides, Trichuris trichiura and food-borne trematodes. Third, the time required for collecting the stool specimens in the field, transferring them to the laboratory, and preparing the slides for examination can result in significant underestimates of hookworm burdens [36]. As a compromise, in settings where soil-transmitted helminths co-exist with either S. mansoni or food-borne trematodes, KatoKatz thick smears are often examined 30-60 min after preparation. Fourth, the Kato-Katz technique is not suitable for the diagnosis of Strongyloides stercoralis, which might, at least partially, explain why this is the most neglected of the soil-transmitted helminths $[8,20,37]$.

\section{Transmission control - egg detection subsequently replaced}

The need for accurate and precise diagnostic tests increases strongly when the overall performance decreases towards the low-prevalence end. The standard Kato-Katz technique is a good example of how this diagnostic process works. Although Kato-Katz is a sound approach for highly endemic areas $[38,39]$, it is inadequate in situations characterized by a low infection intensities and few infected people [6,40]. Hence, in the latter case (which is typical for the transmission control stage), the positive predictive value of the test decreases, which above all calls for highly sensitive assays but of course also with acceptable specificity. In this situation, it is obvious that further progress in controlling a disease - and ultimately local elimination - is jeopardized. FLOTAC ${ }^{\circledR}$, a new technique for stool examination so far mainly used in the veterinary field, holds promise in relation to this dilemma. Recent studies found that a single FLOTAC ${ }^{\circledR}$ examination is more sensitive than multiple Kato-Katz thick smears for hookworm diagnosis [41], as well as A. lumbricoides and T. trichiura diagnosis 
[42]. In addition, multiple stool (or urine or sputum) examinations and the use of different methods simultaneously should be considered [37,43-45].

Thus, once morbidity is under control, further progress demands more sensitive techniques and when the transmission and surveillance control stages have been reached, cost might increase as control at these levels not only must consider different kinds of host (example: schistosomiasis; see Table 1), but also requires even more sensitive approaches. At this stage, antibody-detection is clearly the preferential, primary approach for monitoring the human population [39]. Of note, in the Chinese national schistosomiasis control programme, serology is routinely implemented, usually followed by stool examination of sero-positive individuals [7]. However, there are many challenges to this course of action. First, antibodydetection is not quantitative. Second, it fails to distinguish between current and cured infection, although progress has been made to remedy this issue [39]. Third, the high degree of cross-reactivity with clonorchiasis and paragonimiasis is a problem of particular importance in China and the countries south of its border where these food-borne trematode infections are highly endemic $[12,13,15]$. In areas where antibody-detection is challenged by significant cross-reactivity, molecular tools should be contemplated in spite of their higher cost and requirement for speciality laboratories. For example, in Brazil, polymerase chain reaction (PCR) applied to human faeces found a prevalence of $38.1 \%$ in a study of 194 individuals from a S. mansoni-endemic area, while triplicate Kato-Katz thick smears achieved only $30.9 \%$ prevalence in the same samples [46]. PCR approaches have also been successfully developed for a number of other helminths, including food-borne trematodes [47]. Fourth, integration of this type of serology into national control programmes requires access to affordable, high-quality reagents or kits, as well as successful methodological standardization and definition of assay performance. These points might explain why only few countries have adopted antibody-detection as a key strategy in helminth diagnosis. This notwithstanding, it is 
likely that antibody-detection will gain in importance as further progress is being made with controlling helminth infections [39].

\section{Post-transmission control - imaging techniques}

Recent progress in the use of imaging techniques for helminthic diseases $[13,48,49]$ has shown that pathology remains a problem long after the infection has been successfully treated. Based on experience from Japan, surgical and other interventions may increasingly be needed on an individual basis in settings where transmission of trematode infections has been interrupted. This is currently a totally neglected problem which needs to be budgeted for as a final outlay when elimination is in sight.

\section{Research needs}

Intensity of infection is a key determinant of morbidity, but the relation between egg excretion in stool (or urine or sputum) and severity of disease is complex [11]. Attempts have been made to classify helminth infection intensities based on egg counts (Table 2). However, these classifications are educated guesses at best and new research is warranted to put forth new or refined infection intensity classes for the helminthiases covered here. Indeed, morbidity cannot be assessed without clinical examination and sound imaging techniques $[13,48,49]$. Nevertheless, there is a possibility that laboratory testing could be a useful adjunct. For example, a quantitative assay has been developed for schistosomiasis-related bladder lesions, which relies on the excretion of an eosinophilic cationic protein (ECP) in the urine [50] and this approach may be possible to use also for faecal investigations [51].

While stool examination provides an acceptable measure of the stage of infection in highly endemic areas, there was originally hope that antigen-detection would do the same at the other end of the control spectrum, i.e. in areas of very low endemicity. However, this has 
not been validated as antigen detection techniques are only marginally more sensitive than stool examination. Although serology and microscopy are complementary, it cannot be emphasized enought that the integration of serological methods into national control programmes requires development of accurate, methodologically standardized and easily applicable assays for the detection of both specific antibodies and antigens.

Although, most countries are still far from elimination with respect to the helminthiases discussed here, it makes sense to already now consider what is required to permit an area or entire country to be formally declared as eliminated from an infection. Would it suffice to present a certain number of negative results, over a specified time period, based on an absolutely specific, highly sensitive assay, such as PCR, in conjunction with negative serology?

The issues discussed here are not the only ones that can introduce failings as large-scale helminth control programmes continue to advance but the identification of the main diagnostic obstacles and dilemmas will facilitate the finding of logical, relatively straightforward ways to address them. The opinions expressed here are intended as an incitement to further enlargement of the scope of helminth diagnosis leading to multi-country studies aimed at standardizing protocols for rigorous validation of different diagnostic assays so that they can be utilized with high levels of confidence at different stages of control interventions.

\section{Acknowledgements}

We wish to thank Dr Lester Chitsulo for initiating an informal consultation at WHO to discuss some of the diagnostic dilemmas in helminthology expressed here. J. Utzinger acknowledges financial support from the Swiss National Science Foundation (project no. PPOOB--102883; PPOOB--119129). 


\section{References}

226

227

1 Ridley, R.G. (2006) Diagnostics take centre stage. Nat Rev Microbiol 4 (9 Suppl.), S1

2 Gottstein, B. and Piarroux, R. (2008) Current trends in tissue-affecting helminths. Parasite 15, 291-298

3 Ruiz-Tiben, E. and Hopkins, D.R. (2006) Dracunculiasis (Guinea worm disease) eradication. Adv Parasitol 61, 275-309

4 Lammie, P.J. et al. (2006) A blueprint for success: integration of neglected tropical disease control programmes. Trends Parasitol 22, 313-321

5 Ottesen, E.A. (2006) Lymphatic filariasis: treatment, control and elimination. Adv Parasitol 61, 395-441

6 Zhu, Y.C. (2005) Immunodiagnosis and its role in schistosomiasis control in China: a review. Acta Trop 96, 130-136

7 Fenwick, A. et al. (2006) Implementation of human schistosomiasis control: challenges and prospects. Adv Parasitol 61, 567-622

8 Bethony, J. et al. (2006) Soil-transmitted helminth infections: ascariasis, trichuriasis, and hookworm. Lancet 367, 1521-1532

9 Steinmann, P. et al. (2006) Schistosomiasis and water resources development: systematic review, meta-analysis, and estimates of people at risk. Lancet Infect Dis 6, 411-425

10 Hotez, P.J. et al. (2008) Helminth infections: the great neglected tropical diseases. J Clin Invest 118, 1311-1321

11 WHO (2002) Prevention and control of schistosomiasis and soil-transmitted helminthiasis: report of a WHO expert committee. WHO Tech Rep Ser No. 912

12 Keiser, J. and Utzinger, J. (2005) Emerging foodborne trematodiasis. Emerg Infect Dis $11,1507-1514$ 
13 Lun, Z.R. et al. (2005) Clonorchiasis: a key foodborne zoonosis in China. Lancet Infect Dis 5, 31-41

14 McManus, D.P. and Dalton, J.P. (2006) Vaccines against the zoonotic trematodes Schistosoma japonicum, Fasciola hepatica and Fasciola gigantica. Parasitology 133 (Suppl.), S43-61

15 Liu, Q. et al. (2008) Paragonimiasis: an important food-borne zoonosis in China. Trends Parasitol 24, 318-323

16 Sripa, B. (2008) Concerted action is needed to tackle liver fluke infections in Asia. PLoS Negl Trop Dis 2, e232

17 The TDR Diagnostics Evaluation Expert Panel (2006) Evaluation of diagnostic tests for infectious diseases: general principles. Nat Rev Microbiol 4 (9 Suppl.), S21-31

18 Peeling, R.W. et al. (2006) A guide for diagnostic evaluations. Nat Rev Microbiol 4 (9 Suppl.), S2-6

19 Engels, D. et al. (2002) The global epidemiological situation of schistosomiasis and new approaches to control and research. Acta Trop 82, 139-146

20 Engels, D. and Savioli, L. (2006) Reconsidering the underestimated burden caused by neglected tropical diseases. Trends Parasitol 22, 363-366

21 Brooker, S. and Utzinger, J. (2007) Integrated disease mapping in a polyparasitic world. Geospat Health 1, 141-146

22 Giboda, M. and Bergquist, N.R. (2000) Post-transmission schistosomiasis: a new agenda. Acta Trop 77, 3-7

23 Brady, M.A. et al. (2006) Projected benefits from integrating NTD programs in subSaharan Africa. Trends Parasitol 22, 285-291

24 Fenwick, A. (2006) New initiatives against Africa's worms. Trans R Soc Trop Med Hyg 100, 200-207 
25 Kolaczinski, J.H. et al. (2007) Neglected tropical diseases in Uganda: the prospect and challenge of integrated control. Trends Parasitol 23, 485-493

26 Jordan, P. (2000) From Katayama to the Dakhla Oasis: the beginning of epidemiology and control of bilharzia. Acta Trop 77, 9-40

27 WHO (1985) The control of schistosomiasis: report of a WHO expert committee. WHO Tech Rep Ser No. 728

28 Lengeler, C. et al. (2002) Questionnaires for rapid screening of schistosomiasis in subSaharan Africa. Bull World Health Organ 80, 235-242

29 Dang, T.C. et al. (2008) Prevalence, intensity and risk factors for clonorchiasis and possible use of questionnaires to detect individuals at risk in northern Vietnam. Trans $R$ Soc Trop Med Hyg 102, 1263-1268

30 Strandgaard, H. et al. (2008) Local perceptions and practices in regard to opisthorchiasis in two villages in Lao PDR. Southeast Asian J Trop Med Public Health 39, 19-26

31 Katz, N. et al. (1972) A simple device for quantitative stool thick-smear technique in schistosomiasis mansoni. Rev Inst Med Trop Sao Paulo 14, 397-400.

32 Rim, H.J. et al. (2003) Prevalence of intestinal parasite infections on a national scale among primary schoolchildren in Laos. Parasitol Res 91, 267-272

33 Guyatt, H. (1998) Different approaches to modelling the cost-effectiveness of schistosomiasis control. Mem Inst Oswaldo Cruz 93 (Suppl. 1), 75-84

34 Doenhoff, M.J. et al. (2008) Praziquantel: mechanisms of action, resistance and new derivatives for schistosomiasis. Curr Opin Infect Dis 21, 659-667

35 Trung Dung, D. et al. (2007) Fishborne zoonotic intestinal trematodes, Vietnam. Emerg Infect Dis 13, 1828-1833

36 Dacombe, R.J. et al. (2007) Time delays between patient and laboratory selectively affect accuracy of helminth diagnosis. Trans $R$ Soc Trop Med Hyg 101, 140-145 
37 Steinmann, P. et al. (2007) Occurrence of Strongyloides stercoralis in Yunnan province, China, and comparison of diagnostic methods. PLoS Negl Trop Dis 1, e75

38 Booth, M. et al. (2003) The influence of sampling effort and the performance of the Kato-Katz technique in diagnosing Schistosoma mansoni and hookworm co-infections in rural Côte d'Ivoire. Parasitology 127, 525-531

39 Doenhoff, M.J. et al. (2004) Specific and sensitive diagnosis of schistosome infection: can it be done with antibodies? Trends Parasitol 20, 35-39

40 Enk, M.J. et al. (2008) A combined strategy to improve the control of Schistosoma mansoni in areas of low prevalence in Brazil. Am J Trop Med Hyg 78, 140-146

41 Utzinger, J. et al. (2008) FLOTAC: a new sensitive technique for the diagnosis of hookworm infections in humans. Trans R Soc Trop Med Hyg 102, 84-90

42 Knopp, S. et al. (2009). A single FLOTAC is more sensitive than triplicate Kato-Katz for diagnosis of low-intensity soil-transmitted helminth infections. Trans $R$ Soc Trop Med Hyg 103, (in press).

43 de Vlas, S.J. and Gryseels, B. (1992) Underestimation of Schistosoma mansoni prevalences. Parasitol Today 8, 274-277

44 Knopp, S. et al. (2008) Diagnosis of soil-transmitted helminths in the era of preventive chemotherapy: effect of multiple stool sampling and use of different diagnostic techniques. PLoS Negl Trop Dis 2: e331

45 Steinmann, P. et al. (2008) Extensive multiparasitism in a village of Yunnan province, People's Republic of China, revealed by a suite of diagnostic methods. Am J Trop Med Hyg 78, 760-769

46 Eberl, M. et al. (2002) A novel and sensitive method to monitor helminth infections by faecal sampling. Acta Trop 83, 183-187 
47 Duenngai, K. et al. (2008) Improvement of PCR for detection of Opisthorchis viverrini DNA in human stool samples. J Clin Microbiol 46, 366-368

48 Khandelwal, N. et al. (2008) Biliary parasites: diagnostic and therapeutic strategies. Curr Treat Options Gastroenterol 11, 85-95

49 Lambertucci, J.R. et al. (2008) Imaging techniques in the evaluation of morbidity in schistosomiasis mansoni. Acta Trop 108 (in press)

50 Leutscher, P.D.C. et al. (2000) Morbidity assessment in urinary schistosomiasis infection through ultrasonography and measurement of eosinophil cationic protein (ECP) in urine. Trop Med Int Health 5, 88-93

51 Reimert, C.M. et al. (2008) Assessment of Schistosoma mansoni induced intestinal inflammation by means of eosinophil cationic protein, eosinophil protein $\mathrm{X}$ and myeloperoxidase before and after treatment with praziquantel. Acta Trop 105, 253-259.

52 Sadun, E.H. (1955) Studies on Opisthorchis viverrini in Thailand. Am J Hyg 62, 81-115 
Accuracy: the percentage of correct results obtained by a test under evaluation compared with the results of a reference or 'gold' standard test.

Community effectiveness: the ability of a particular intervention to alter the natural history of a particular disease for the better, under actual conditions of practice and use.

Cost-effective: producing good results for the amount of money spent.

Efficacy: the ability of an intervention to produce the desired beneficial effect under ideal circumstances (assessed by randomized controlled trials).

Elimination: reduction to zero of the incidence of a specific disease/infection caused by a specific agent in a defined geographical area as a result of deliberate efforts.

Eradication: permanent reduction to zero of the worldwide incidence of infection caused by a specific agent as a result of deliberate efforts.

Precision: the degree to which repeated measurements or calculations show the same or similar results.

Positive predictive value: the probability that a positive result accurately indicates the presence of infection.

Sensitivity: the proportion of actual positives which are correctly identified as such (i.e. the percentage of sick people who are identified as having the condition).

Specificity: the proportion of negatives which are correctly identified (i.e. the percentage of well people who are identified as not having the condition). 

programmes (exemplified by schistosomiasis)

\begin{tabular}{|c|c|c|c|c|c|}
\hline \multirow[t]{2}{*}{ Characteristics } & \multicolumn{5}{|c|}{ Stage of helminth control programme } \\
\hline & Morbidity & Prevalence & Transmission & Surveillance & Elimination \\
\hline Target & - Human host & - Human host & $\begin{array}{l}\text { - Human host } \\
\text { - Reservoir host } \\
\text { - Intermediate } \\
\text { host }\end{array}$ & $\begin{array}{l}\text { - Human host } \\
\text { - Reservoir host } \\
\text { - Intermediate } \\
\text { host }\end{array}$ & $\begin{array}{l}\text { - Human host } \\
\text { - Reservoir host } \\
\text { - Intermediate } \\
\text { host }\end{array}$ \\
\hline Diagnostic traits & $\begin{array}{l}\text { - Simplicity } \\
\text { - Low cost }\end{array}$ & $\begin{array}{l}\text { - Sensitivity } \\
\text { - Specificity }\end{array}$ & $\begin{array}{l}\text { - High sensitivity } \\
\text { - Specificity }\end{array}$ & $\begin{array}{l}\text { - High sensitivity } \\
\text { - Specificity }\end{array}$ & $\begin{array}{l}\text { - High sensitivity } \\
\text { - High specificity }\end{array}$ \\
\hline $\begin{array}{l}\text { Suggested } \\
\text { approach }\end{array}$ & $\begin{array}{l}\text { - Questionnaire } \\
\text { - Microscopy }\end{array}$ & $\begin{array}{l}\text { - Sensitive direct } \\
\text { tests }\end{array}$ & $\begin{array}{l}\text { - Antigen } \\
\text { detection } \\
\text { - Labelled } \\
\text { antibody }^{\mathrm{a}}\end{array}$ & $\begin{array}{r}\text { - Antibody } \\
\text { detection }\end{array}$ & $\begin{array}{l}\text { - PCR } \\
\text { - Antibody } \\
\text { detection }\end{array}$ \\
\hline $\begin{array}{l}\text { Strength and } \\
\text { limitations }\end{array}$ & $\begin{array}{l}\text { - Good indicator } \\
\text { of general } \\
\text { status } \\
\text { - Neglect light } \\
\text { infections }\end{array}$ & $\begin{array}{l}\text { Development } \\
\text { of test system } \\
\text { not completed }\end{array}$ & $\begin{array}{l}\text { - Antigen } \\
\text { detection not } \\
\text { sufficiently } \\
\text { sensitive } \\
\text { - Vector test } \\
\text { complicated }\end{array}$ & $\begin{array}{l}\text { - Excellent } \\
\text { sensitivity } \\
\text { - } \text { Cross reactions } \\
\text { and specificity } \\
\text { problems } \\
\text { - Specific titres } \\
\text { remain high for } \\
\text { long time }\end{array}$ & $\begin{array}{l}\text { - Capable assays } \\
\text { - Certified } \\
\text { testing } \\
\text { - System not yet } \\
\text { available } \\
\end{array}$ \\
\hline
\end{tabular}



counts $^{\mathrm{a}}$

\begin{tabular}{|c|c|c|c|c|c|}
\hline \multirow[t]{2}{*}{ Parasite investigated } & \multirow[t]{2}{*}{ Unit of measure } & \multicolumn{3}{|c|}{ Infection intensity } & \multirow[t]{2}{*}{ Reference } \\
\hline & & Light & Moderate & Heavy & \\
\hline \multicolumn{6}{|l|}{ Schistosomes } \\
\hline Schistosoma mansoni & EPG & $1-99$ & 100-399 & $\geq 400$ & [11] \\
\hline Schistosoma haematobium & Eggs $/ 10 \mathrm{ml}$ urine & $1-49$ & $\geq 50$ & $\geq 50$ & [11] \\
\hline \multicolumn{6}{|l|}{ Soil-transmitted helminths } \\
\hline Ascaris lumbricoides & EPG & $1-4999$ & $5000-49999$ & $\geq 50000$ & [11] \\
\hline Hookworm & EPG & $1-1999$ & 2000-3999 & $\geq 4000$ & [11] \\
\hline Trichuris trichiura & EPG & $1-999$ & $1000-9999$ & $\geq 10000$ & [11] \\
\hline \multicolumn{6}{|l|}{ Food-borne trematodes } \\
\hline Clonorchis sinensis & EPG & tbd & tbd & tbd & - \\
\hline Fasciola hepatica & EPG & tbd & tbd & tbd & - \\
\hline Fasciola gigantica & EPG & tbd & tbd & tbd & - \\
\hline Opisthorchis viverrini & EPG & $1-999$ & $1000-9999$ & $\geq 10000$ & [52] \\
\hline Paragonimus spp. & EPG & tbd & tbd & tbd & - \\
\hline
\end{tabular}


372 Figure 1. Schematic picture illuminating how falling endemicity levels influence control focus 373 and diagnostic needs.

Figure 2. Current and suggested use of available tools for the diagnosis of major helminth 376 infections.

377 
Endemicity

Focus

Goal

Diagnostic preference

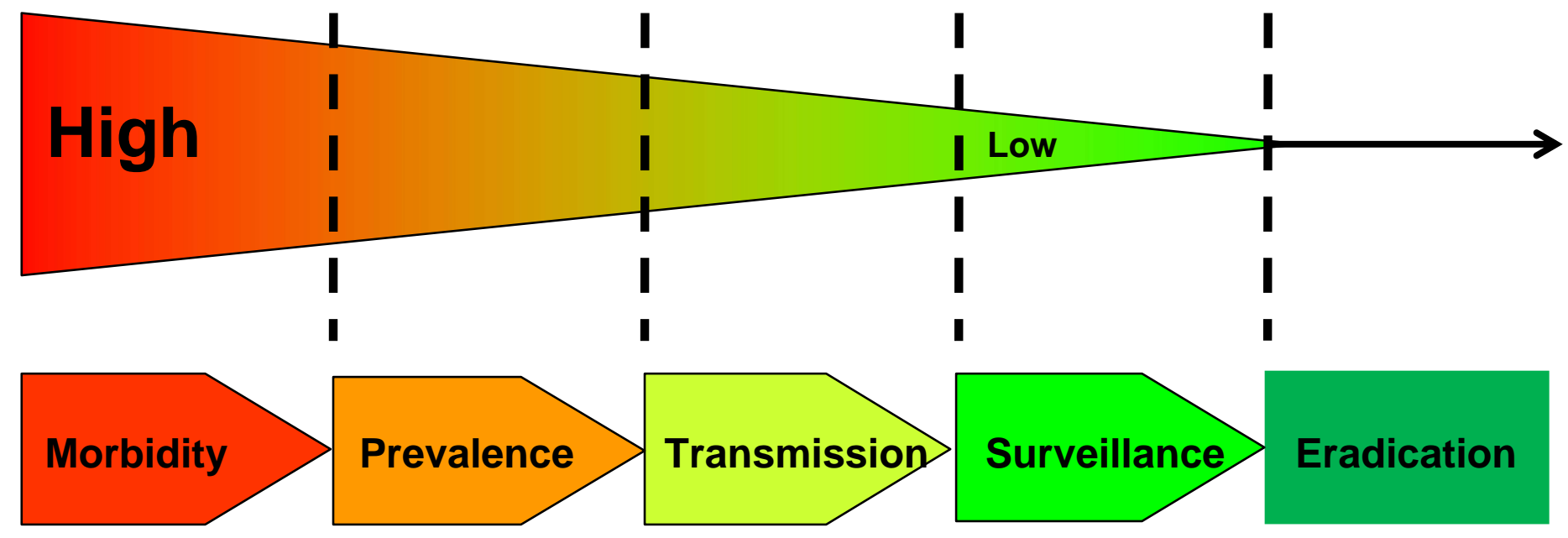

Reduced infection intensity

Reduced number of cases

Reduced risk for infection*

Elimination as a public health threat

Endemicity status revoked *less human behavioural risk and/or fewer infected intermediate hosts
** applies also to assays aimed at the intermediate host 


\section{Stage of control}

Prevalence

\section{Schistosomiasis}

Intestinal

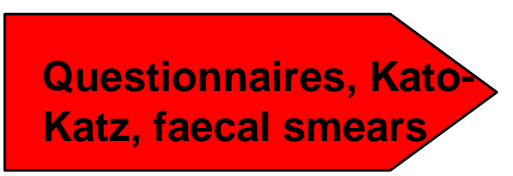

Urinary

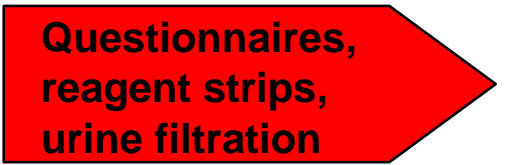

Kato-Katz, antibody detection

Questionnaires, reagent strips, urine filtration

\section{Soil-transmitted helminthiasis}

Ascariasis
Hookworm
Trichuriasis
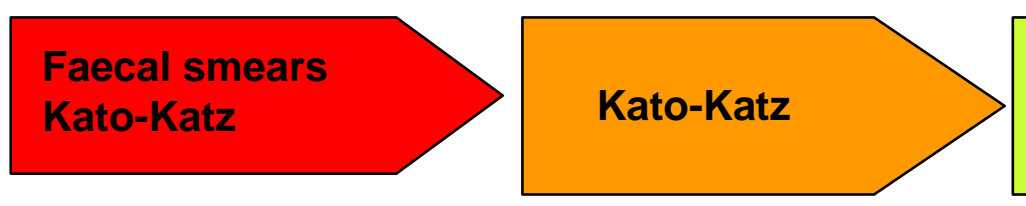

Highly sensitive, direct*
Highly sensitive, direct* $^{*}$

\section{Food-borne trematodiasis}

Clonorciasis
Fascioliasis
Opisthorchiasis
Paragonimiasis

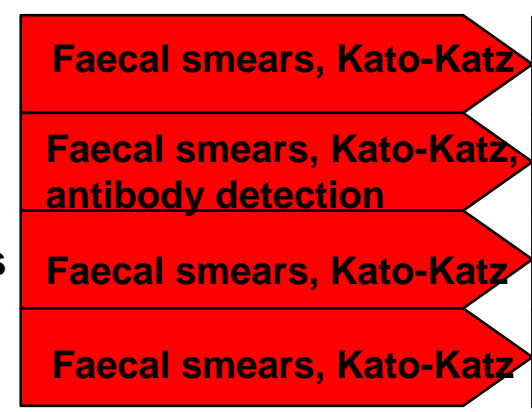

* Refers to tests used to demonstrate any parasite material in the host circulation, tissues or excreta (whole worms, parasite eggs circulating antigens) directly by microscopy, serology or PCR.

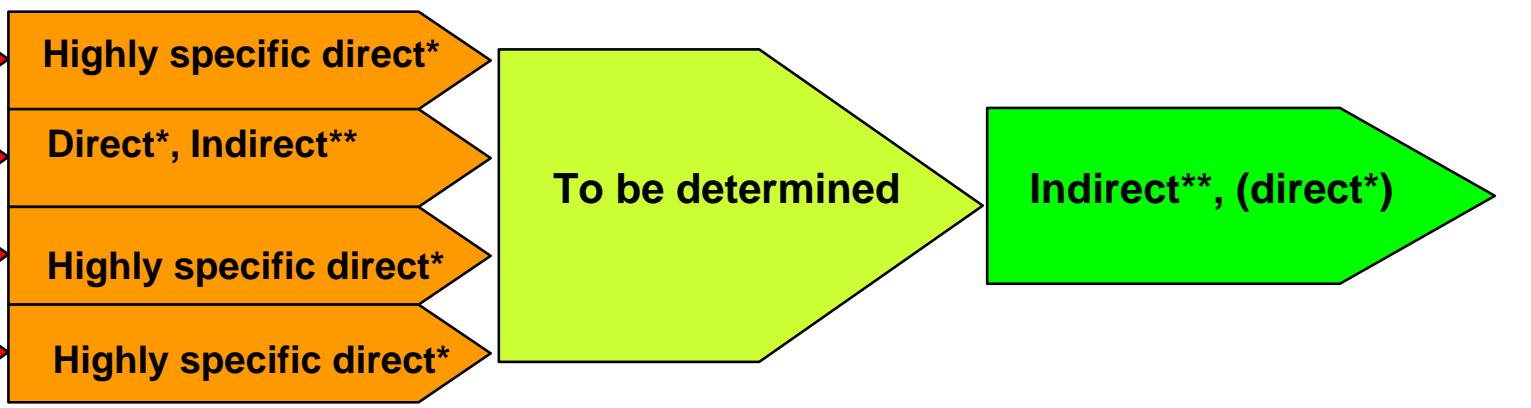

** Refers to results from the use of reagent strips, questionnares, intradermal tests, clinical examination, imaging and antibody detection. 